\title{
ON REFINEMENTS OF CAUCHY'S INEQUALITY AND HÖLDER'S INEQUALITY
}

\author{
G. HORVÁTH
}

Abstract. The aim of this paper is to give refinements of Hölder's inequality by a sharpening of Cauchy's inequality.

Mathematics subject classification (2010): 26D15, 46E30.

Keywords and phrases: Cauchy's inequality, Hölder's inequality, refinement.

\section{REFERENCES}

[1] J. M. Aldaz, A stability version of Hölder's inequality, J. Math. Anal. Appl., 343 (2008), 842-852.

[2] X. GAO, M. GAO, X. SHANG, A refinement of Hölder's inequality and applications, J. Inequal. Pure and Appl. Math., 8 (2) (2007), Art. 44, 9 pp. 